\title{
Drinking and smoking at 3 months postpartum by lactation history
}

\author{
Ruth E. Little*, M. Dow Lambert $†$ and Bonnie \\ Worthington-Roberts $\ddagger \S$ \\ *Department of Epidemiology, University of Michigan, Ann Arbor, \\ Departments of $\nmid$ Psychiatry and $\ddagger$ Epidemiology and §Child \\ Development and Mental Retardation Center, University of \\ Washington, Seattle, USA
}

Summary. A spontaneous decrease in maternal drinking and smoking often occurs during pregnancy. The present study was conducted to determine if these lower levels of maternal drinking and smoking during pregnancy persist into the postpartum period, and if so, to determine if they are related to breastfeeding. Drinking and smoking were estimated in three cohorts of postpartum women who had been followed since pregnancy. The first group never breastfed their infants; the second group breastfed for less than 1 month; the third group breastfed for more than three months. (Women who weaned between one and three months were not studied.) Drinking and smoking in all three groups decreased sharply during pregnancy but rose again in the 3 months after delivery, though not to levels that were reported before conception. Usual drinking in the third month postpartum did not differ significantly among the three lactation groups. However, women who were still nursing were less likely to report occasional episodes of heavy drinking (binges) in this month than women who had weaned early or never breastfed. Women nursing in the third month postpartum were also significantly less likely to smoke during the month; if smoking, they were less likely to smoke heavily. These differences in postpartum drinking and smoking were not due entirely to habits before conception or to the influence of other potentially confounding variables.

Address for correspondence: Ruth E. Little, Department of Epidemiology, University of Michigan, 109 Observatory, Ann Arbor, MI 48109, USA. 


\section{Introduction}

Alcohol and nicotine cross the placenta when ingested by the mother during pregnancy. Fetal exposure to these toxins has been associated with growth retardation, developmental anomalies and neurobehavioural changes. ${ }^{1,2}$ Endogenous maternal aversions to alcohol and tobacco occur in perhaps half of all pregnant women, and some investigators have suggested that they are fetoprotective. ${ }^{3,4}$

Alcohol and nicotine also enter the breast milk. ${ }^{5-8}$ Information on the effect of these substances on the human infant is limited to occasional reports of intoxication or illness when the mother smoked or drank heavily. ${ }^{9-11}$ Animal studies suggest disrupted growth and development with exposure to alcohol and nicotine via breast milk. ${ }^{12-15}$ In the case of nicotine, this may be due to interference with milk production. ${ }^{16,17} \mathrm{~A}$ few studies indicate that in animals, the aversion to drinking during pregnancy persists into lactation. ${ }^{18-21}$ Whether human appetite for alcohol and tobacco continues below usual prepregnancy levels, and whether such a lowered level would be beneficial to a nursing infant is unknown.

The purpose of this study was to describe human alcohol and tobacco use in the postpartum period, and to compare it to alcohol and tobacco use prior to conception and during pregnancy. We expected that levels of drinking and smoking in the third month of the postpartum period would be lower among women who were still nursing than among women who had breastfed for only a short time or not at all.

\section{Methods}

\section{Subjects}

The present study was one of several related investigations of maternal diet, drinking and smoking during lactation and their role in infant growth and development. Subjects for these investigations were recruited from Group Health Cooperative of Puget Sound, a health maintenance organisation in Seattle, Washington. All prenatal patients were contacted by the Cooperative in their sixth month of gestation and asked to return a postcard to our research office regarding possible study participation. Patients who began prenatal care after the sixth month of gestation were not eligible for study. Seventy-four per cent of the prenatal patients returned the card and also completed a mail screening questionnaire giving their plans to lactate and information on diet, drinking and smoking. An informed consent agreement with a full explanation of study procedures was included.

Subjects in the present study were selected on the basis of their breastfeeding status. 'Breastfeeding' was defined as providing some portion of the infant's diet from breast milk. A 'nursing' mother was one who breastfed her infant and who 
gave less than $470 \mathrm{ml}(16 \mathrm{oz}$ ) of supplemental milk or formula per day. The original study design specified that two cohorts of 200 postpartum women would be compared. One cohort would have nursed their infants for at least 3 months, while the other cohort would never have breastfed at all. Pilot work revealed that so few women never breastfed at all that 200 such subjects could not be recruited within the funding period. Therefore this cohort was expanded to include women who breastfed less than 1 month.

All women who had been contacted by the Cooperative between 1 October 1982 and 1 February 1984, and who had borne a live singleton were telephoned at 1 month postpartum and asked if they were breastfeeding. When a woman reported that she was not breastfeeding when contacted by telephone, she was paired with the next nursing woman available for study who had delivered in the same week, and a subsequent personal interview was scheduled for both. Women who were nursing at the 1 month interview were recontacted at 3 months to verify that they were still nursing; if so, they remained in the study and were reinterviewed at the conclusion of the third postpartum month, as were women in the cohort who were not breastfeeding at 1 month postpartum. Women who had been nursing at the 1 month interview but who had stopped by the time they were recontacted at 3 months were not studied further. This was done in order to restrict the sample to the extreme ends of the breastfeeding distribution in so far as possible, thus maximising the difference in their breastfeeding behaviour.

Six hundred and eleven women were interviewed for the present study at 1 month postpartum. Of these, $9 \%(n=55)$ were nursing at 1 but not 3 months and were thus ineligible to continue. Fourteen per cent $(n=87)$ failed to complete all parts of the study due to refusal, moving, baby's death, maternal illness, etc.; there was no difference in the proportion of these by lactation status. One per cent $(n=6)$ became pregnant again by the third postpartum month and were excluded because pregnancy would change the usual postpartum patterns of diet, drinking and smoking. The final sample consisted of 220 women who had nursed for at least 3 months and 243 women who had weaned by 1 month postpartum.

\section{Data collection}

Data were collected for five time periods: the month before conception; the first 6 months of pregnancy; the last 3 months of pregnancy; the first postpartum month; and the third postpartum month. The screening questionnaire that was sent to all subjects at 6 months of pregnancy gathered data for the month before conception and for the pregnancy to date. A personal interview conducted after the first postpartum month obtained information for the last trimester of pregnancy and for the first month after delivery. An interview was also conducted after the third postpartum month. Questions about alcohol use included frequency of drinking and modal quantity on a drinking day, and how often five or more drinks were 
consumed on a single occasion. Average cigarettes lit per day was also determined.

Before data collection began, we assessed the validity of the alcohol and tobacco self-reports using blood chemistries and a physical exam to identify signs of heavy alcohol use and serum thiocyanate levels to identify smokers. Test results revealed no signs of unreported heavy drinking; two subjects (of 103) underreported their smoking. ${ }^{22}$

Each subject was assigned a single interviewer who was a woman of childbearing age who had been trained to obtain valid and reliable information about diet, drinking and smoking. Interviewers, who were unaware of the study hypothesis, were assigned to both nursing and non-nursing subjects.

\section{Data analysis}

Average daily ounces of ethanol ingested in the period ('AA score') was computed from reports of frequency and quantity of alcohol use by standard methods. ${ }^{23}$ (One ounce [29.4 ml] ethanol is equivalent to about two standard-sized drinks of any beverage.) Alcohol use was also categorised as 'any' drinking, 'regular' drinking and 'binge' drinking. 'Regular' drinking was the ingestion of an average of at least $0.5 \mathrm{oz}$ ethanol (about one drink) daily; a 'binge' was defined as at least $2.5 \mathrm{oz}$ ethanol (about five drinks) on a single occasion. Tobacco use was expressed as 'any' smoking (at least one cigarette daily), number of cigarettes smoked per day, and 'heavy' smoking of 20 cigarettes (one pack) or more daily.

Alcohol and tobacco use before conception were considered as the major potential confounders of any observed relationship between lactation history and alcohol and tobacco use in the postpartum period. In addition, more than 20 independent variables that had been associated with alcohol or tobacco use or with lactation status in other studies were examined as potential confounders. The variables were maternal age, height, usual weight, weight gain during pregnancy, maternal race, marital status and whether living with a partner, family income level and source of income, maternal employment status, maternal education, number of prior pregnancies, live births, fetal deaths and terminations, nausea in the postpartum period, gestational age at delivery, paternal alcohol and tobacco use in the postpartum period, and alcohol and tobacco use by other members of the household in addition to the parents.

Differences among lactation groups in the distribution of categorical variables were evaluated with the chi-square test. One-way analysis of variance was used to evaluate differences across the groups in the means of the AA scores and number of cigarettes smoked. To evaluate differences in month 3 AA score while controlling for AA score before conception, month 3 AA score was regressed on preconception AA score and the residuals (plus the sample mean) were used in a one-way analysis of variance. 
A similar strategy was followed for number of cigarettes. Transformations of AA score and number of cigarettes were also used to verify that the skewed distributions of the variables were not responsible for the observed results, which were confirmed in non-parametric analyses.

Relative risks ${ }^{24}$ were also employed to describe association between the drinking (or smoking) variables and lactation history, taking the lactation groups in pairs. The Mantel-Haenszel summary estimate ${ }^{24}$ was used to express the relative risk while controlling for any confounding variables. Relative risks are shown in this work with $99 \%$ confidence intervals; if the interval contains 1.0 , the relative risk that it encloses is deemed non-significant at the $1 \%$ level.

Formally, the null hypothesis was tested; (two-tailed) $P$ values are presented as less than 0.05 , less than 0.01 and less than 0.001 . If no $P$ value is given, it is at or above 0.05 . The reader is cautioned that the data have been subjected to multiple testing and some findings could be 'statistically significant' by chance.

\section{Findings}

In preliminary analyses, we subdivided the cohort of women nursing at 3 months into those who had provided additional nourishment to their infant during the 3 months after delivery $(n=102)$, and those who did not supplement their breast milk at all $(n=118)$. There were no appreciable differences in demographic or reproductive variables nor in the subjects' use of alcohol and tobacco, so the two were recombined. The other cohort (women not nursing at 1 month) was subdivided into those who had never breastfed and those who had. These two subgroups differed in several ways so they were not recombined. Thus, three sets of subjects were used in succeeding analyses:

(1) Women who nursed (breastfed, with less than 16 oz supplemental formula daily) for at least 3 months postpartum $(n=220)$

(2) Women who breastfed, but who had weaned their infant by 1 month postpartum $(n=112)$. Length of breastfeeding was: $\leq 1$ week, $43 ; 2$ weeks, $30 ; 3$ weeks or more, 39 .

(3) Women who never breastfed, even in the hospital $(n=131)$.

This sample of 463 women was primarily White, middle class and welleducated (Table 1). The three groups differed significantly in marital status, employment status, income, education, age and parity. Women nursing at 3 months were more likely to be married, to have higher income and some college education and to be in their thirties than women in the other groups. Women who weaned early were significantly more likely to be primiparous. Women who never breastfed at all were significantly more likely to be working. Differences among the groups in other variables were small $(P>0.05)$.

Table 2 shows drinking and smoking in the three groups over the five time 
Table 1. Demographic and reproductive characteristics by lactation history

\begin{tabular}{lcccc}
\hline & $\begin{array}{c}\text { Never } \\
\text { lactated } \\
(n=131)\end{array}$ & $\begin{array}{c}\text { Weaned in } \\
\text { first month } \\
(n=112)\end{array}$ & $\begin{array}{c}\text { Nursed } \\
\geq 3 \text { months } \\
(n=220)\end{array}$ & $\begin{array}{c}\text { All } \\
\text { subjects } \\
(n=463)\end{array}$ \\
\hline $\begin{array}{l}\text { Married*** } \\
\text { Working, month 3 postpartum }\end{array}$ & $86 \%$ & $84 \%$ & $99 \%$ & $92 \%$ \\
$\quad$ full or part time)*** & $28 \%$ & $12 \%$ & $7 \%$ & $14 \%$ \\
Income above \$25 000*** & $51 \%$ & $54 \%$ & $60 \%$ & $56 \%$ \\
More than 12 yr school*** & $50 \%$ & $63 \%$ & $79 \%$ & $63 \%$ \\
White race & $91 \%$ & $91 \%$ & $94 \%$ & $93 \%$ \\
Age* & & & & \\
$\quad$ Under 20 & $9 \%$ & $7 \%$ & $2 \%$ & $5 \%$ \\
$20-29$ & $60 \%$ & $63 \%$ & $59 \%$ & $60 \%$ \\
$\quad 30-39$ & $30 \%$ & $30 \%$ & $38 \%$ & $34 \%$ \\
40 or more & $1 \%$ & $0 \%$ & $1 \%$ & $1 \%$ \\
Parity*** & & & & \\
1 & $33 \%$ & $50 \%$ & $36 \%$ & $38 \%$ \\
2 & $43 \%$ & $40 \%$ & $36 \%$ & $39 \%$ \\
3 or more & $24 \%$ & $10 \%$ & $28 \%$ & $23 \%$ \\
\hline
\end{tabular}

*** $P<0.001$ for differences between groups by the chi-squared test.

${ }^{*} P<0.05$ when three categories of age are used: $<20,20-29,30+$.

periods. Nearly $80 \%$ of the 463 women reported drinking some alcohol in the month before conception. After conception, alcohol use dropped, and by the last trimester of pregnancy only $40 \%$ of the 463 subjects reported drinking at all. Drinking rose after delivery, and by the end of the third postpartum month, $69 \%$ of the total sample reported some drinking. All alcohol-use measures followed the same pattern of decrease during pregnancy and slow rise postpartum, though not to preconception levels. The changes over time were consistent in all groups.

Women still nursing at 3 months generally reported less drinking in all time periods, especially less binge drinking, than women in the other two groups. Women who weaned early almost always reported the highest frequency of all drinking patterns. Women who never breastfed tended to be intermediate or more like nursing women.

Tobacco use followed similar patterns over time, dropping after conception and rising after delivery, though the rise was minimal among women who were still nursing at 3 months. Of these, fewer reported smoking in any period; those who did smoked significantly fewer cigarettes than women in the other two groups, and were less likely to report heavy smoking (one pack or more daily).

Did these differences in drinking and smoking reflect differences in usual behaviour before conception, or were they related to the lactation experience 
Table 2. Alcohol and tobacco use before and during pregnancy and in the postpartum period by lactation history

\begin{tabular}{|c|c|c|c|c|}
\hline & $\begin{array}{l}\text { Never } \\
\text { lactated }\end{array}$ & $\begin{array}{l}\text { Weaned in } \\
\text { first month }\end{array}$ & $\begin{array}{c}\text { Nursed } \\
\geq 3 \text { months }\end{array}$ & $\begin{array}{c}\text { All } \\
\text { subjects }\end{array}$ \\
\hline \multicolumn{5}{|l|}{ Any drinking during } \\
\hline Month before pregnancy & $81 \%$ & $86 \%$ & $74 \%$ & $79 \%$ \\
\hline First 2 trimesters** & $44 \%$ & $60 \%$ & $40 \%$ & $46 \%$ \\
\hline Last trimester* & $34 \%$ & $51 \%$ & $39 \%$ & $40 \%$ \\
\hline Month 1 postpartum & $70 \%$ & $74 \%$ & $64 \%$ & $68 \%$ \\
\hline Month 3 postpartum & $70 \%$ & $75 \%$ & $66 \%$ & $69 \%$ \\
\hline (Number in group) & (131) & (112) & $(220)$ & $(463)$ \\
\hline & & & & \\
\hline \multicolumn{5}{|l|}{$\begin{array}{l}\text { Among drinkers } \\
\text { AA score }{ }^{(a)} \text { during: }\end{array}$} \\
\hline Month before pregnancy* & 0.30 & 0.38 & 0.24 & 0.30 \\
\hline First 2 trimesters & 0.04 & 0.08 & 0.04 & 0.05 \\
\hline Last trimester & 0.04 & 0.08 & 0.04 & 0.05 \\
\hline Month 1 postpartum** & 0.20 & 0.32 & 0.15 & 0.21 \\
\hline Month 3 postpartum ${ }^{* *}$ & 0.24 & 0.33 & 0.19 & 0.24 \\
\hline (Number in group) & (113) & (99) & $(176)$ & $(388)$ \\
\hline \multicolumn{5}{|l|}{ Regular drinking during: } \\
\hline Month before pregnancy & $18 \%$ & $28 \%$ & $19 \%$ & $21 \%$ \\
\hline First 2 trimesters & $4 \%$ & $4 \%$ & $3 \%$ & $4 \%$ \\
\hline Last trimester & $4 \%$ & $2 \%$ & $1 \%$ & $2 \%$ \\
\hline Month 1 postpartum* & $14 \%$ & $21 \%$ & $10 \%$ & $14 \%$ \\
\hline Month 3 postpartum* & $12 \%$ & $23 \%$ & $12 \%$ & $15 \%$ \\
\hline (Number in group) & $(113)$ & (99) & $(176)$ & $(388)$ \\
\hline \multicolumn{5}{|l|}{ Binge drinking during: } \\
\hline Month before pregnancy*** & $44 \%$ & $39 \%$ & $19 \%$ & $31 \%$ \\
\hline First 2 trimesters** & $11 \%$ & $16 \%$ & $4 \%$ & $9 \%$ \\
\hline Last trimester*** & $0 \%$ & $9 \%$ & $1 \%$ & $3 \%$ \\
\hline Month 1 postpartum*** & $13 \%$ & $19 \%$ & $3 \%$ & $10 \%$ \\
\hline Month 3 postpartum *** & $10 \%$ & $22 \%$ & $4 \%$ & $11 \%$ \\
\hline (Number in group) & (113) & (99) & $(176)$ & $(388)$ \\
\hline \multicolumn{5}{|l|}{ Any smoking during } \\
\hline Month before pregnancy ${ }^{* * *}$ & $32 \%$ & $34 \%$ & $13 \%$ & $23 \%$ \\
\hline First 2 trimesters**** & $30 \%$ & $33 \%$ & $10 \%$ & $21 \%$ \\
\hline Last trimester**** & $25 \%$ & $27 \%$ & $5 \%$ & $16 \%$ \\
\hline Month 1 postpartum *** & $28 \%$ & $32 \%$ & $7 \%$ & $19 \%$ \\
\hline Month 3 postpartum *** & $30 \%$ & $34 \%$ & $8 \%$ & $20 \%$ \\
\hline (Number in group) & (131) & (112) & $(220)$ & $(463)$ \\
\hline \multicolumn{5}{|l|}{ Among smokers ${ }^{2}$} \\
\hline \multicolumn{5}{|l|}{ Mean daily cigarettes during: } \\
\hline Month before pregnancy & 19 & 21 & 16 & 19 \\
\hline First 2 trimesters & 12 & 15 & 9 & 12 \\
\hline Last trimester* & 12 & 12 & 6 & 10 \\
\hline Month 1 postpartum ${ }^{* * *}$ & 16 & 16 & 8 & 14 \\
\hline Month 3 postpartum** & 15 & 17 & 9 & 14 \\
\hline (Number in group) & (44) & $(40)$ & $(28)$ & $(112)$ \\
\hline \multicolumn{5}{|l|}{ Heavy smoking during: } \\
\hline Month before pregnancy & $64 \%$ & $70 \%$ & $46 \%$ & $62 \%$ \\
\hline First 2 trimesters & $36 \%$ & $42 \%$ & $29 \%$ & $37 \%$ \\
\hline Last trimester & $32 \%$ & $40 \%$ & $21 \%$ & $32 \%$ \\
\hline Month 1 postpartum** & $57 \%$ & $48 \%$ & $21 \%$ & $45 \%$ \\
\hline Month 3 postpartum* & $50 \%$ & $52 \%$ & $21 \%$ & $44 \%$ \\
\hline (Number in group) & $(44)$ & $(40)$ & $(28)$ & (112) \\
\hline
\end{tabular}

*** $P<0.001$ for differences between groups.

** $P<0.01$ for differences between groups.

$* P<0.05$ for differences between groups.

Otherwise, $P \geqslant 0.05$.

${ }^{1}$ Sample is all persons reporting drinking during any of the five time periods.

${ }^{2}$ Sample is all persons reporting smoking during any of the five time periods.

(a) AA score is average daily oz ethanol in the period. 
Table 3. Alcohol and tobacco use patterns in the third month postpartum among women who reported these patterns before conception by lactation history

\begin{tabular}{|c|c|c|c|c|}
\hline Third month patterns & $\begin{array}{l}\text { Never } \\
\text { lactated }\end{array}$ & $\begin{array}{l}\text { Weaned in } \\
\text { first month }\end{array}$ & $\begin{aligned} & \text { Nursed } \\
\geq & 3 \text { months }\end{aligned}$ & $\begin{array}{c}\text { All } \\
\text { subjects }\end{array}$ \\
\hline \multicolumn{5}{|l|}{ Drinkers before conception: } \\
\hline$\%$ drinking in third month & $\begin{array}{l}82 \% \\
(105)\end{array}$ & $\begin{array}{l}84 \% \\
(96)\end{array}$ & $\begin{array}{l}84 \% \\
(164)\end{array}$ & $\begin{array}{l}83 \% \\
(365)\end{array}$ \\
\hline $\begin{array}{l}\text { Mean AA score corrected for } \\
\text { preconception drinking: } \\
\text { third month drinkers only }\end{array}$ & 0.33 & 0.39 & 0.32 & 0.34 \\
\hline $\begin{array}{l}\text { Regular drinkers before conception: } \\
\% \text { regular drinking in third month }\end{array}$ & $\begin{array}{l}45 \% \\
(20)\end{array}$ & $\begin{array}{l}59 \% \\
(27)\end{array}$ & $\begin{array}{l}46 \% \\
(33)\end{array}$ & $\begin{array}{r}50 \% \\
(80)\end{array}$ \\
\hline $\begin{array}{l}\text { Bingers before conception: } \\
\% \text { binging in third month** }\end{array}$ & $\begin{array}{l}16 \% \\
(50)\end{array}$ & $\begin{array}{l}36 \% \\
(39)\end{array}$ & $\begin{array}{r}9 \% \\
(34)\end{array}$ & $\begin{array}{l}20 \% \\
(123)\end{array}$ \\
\hline $\begin{array}{l}\text { Smokers before conception: } \\
\% \text { smoking in third month }\end{array}$ & $\begin{array}{l}91 \% \\
(42)\end{array}$ & $\begin{array}{l}95 \% \\
(38)\end{array}$ & $\begin{array}{l}64 \% \\
(28)\end{array}$ & $\begin{array}{l}85 \% \\
(108)\end{array}$ \\
\hline $\begin{array}{l}\text { Mean cigarettes daily } \\
\text { corrected for } \\
\text { preconception smoking: } \\
\text { third month smokers only }\end{array}$ & 17 & 16 & 14 & 16 \\
\hline $\begin{array}{l}\text { Heavy smokers before conception: } \\
\% \text { smoking heavily in third month }\end{array}$ & $\begin{array}{l}69 \% \\
(29)\end{array}$ & $\begin{array}{l}71 \% \\
(28)\end{array}$ & $\begin{array}{l}38 \% \\
(13)\end{array}$ & $\begin{array}{l}64 \% \\
(70)\end{array}$ \\
\hline
\end{tabular}

Total no. of cases in each group in brackets.

*** $P<0.001$ for differences between groups.

${ }^{* *} P<0.01$ for differences between groups.

${ }^{*} P<0.05$ for differences between groups.

Otherwise $P \geq 0.05$.

(a) Categorical variables corrected for preconception use with the Mantel-Haenszel method. Continuous variables corrected by regressing third month value on preconception value and adding sample mean to the residuals.

itself? To address this question, we stratified by drinking or smoking habits before pregnancy.

Table 3 shows that among the women who drank in the month before conception, $83 \%$ reported drinking in month 3 as well, and there was virtually no difference by lactation history. AA score and regular drinking were also consistent across the three groups after preconception habits had been taken into account. However, among the women who binged before conception, nursing women were least likely and women who weaned early most likely to report binging 
postpartum; this difference was statistically significant at the 0.01 level. A similar analysis of smoking and heavy smoking revealed that smokers before conception were significantly less likely to be smoking in the third month postpartum if they were nursing, and heavy smokers before conception were less likely to continue to smoke heavily. The differences in smoking and binge drinking habits of the lactation history groups at three months postpartum were thus not explained solely by usual preconception habits.

Similar tabulations were made for women who were not drinkers, smokers, etc., before conception. Their postpartum behaviour was virtually unchanged. (These data are not presented in tabular form since so little variability was present.)

The sharpest differences in drinking and smoking patterns were between women who weaned in the first month after delivery and women who continued to nurse for at least 3 months. First, we compared these two groups using relative risks for month 3 drinking and smoking variables, adjusted for preconception habits. In Table 4, a relative risk of 1.0 shows that women who weaned in the first month and women still nursing were equally likely to report some drinking in the third month postpartum. A higher probability of regular drinking in the former group was apparent $(R R=1.4)$ but the confidence interval contained 1.0, suggesting that the finding could reasonably be ascribed to chance. Binge drinking, smoking and heavy smoking all had relative risks significantly above 1.0 , indicating that women who weaned in the first month were more likely to report this behaviour at 3 months postpartum than women who were still nursing, even after preconception habits were taken into account.

Data in Table 4 also shows that the drinking patterns of women who never breastfed were not significantly different from those of women who were still nursing at 3 months postpartum. None of the relative risks comparing nonbreastfeeders to the long-term nursing women are significantly different from 1.0. However, non-breastfeeders were significantly more likely than nursing women to smoke and smoke heavily.

There were important differences among the three groups in the demographic and reproductive characteristics listed in Table 1, but adjusting for these did not change the results seen in Tables 3 and 4 .

\section{Conclusions and implications}

The results of this study indicate that drinking and smoking decreased sharply after conception and began to increase after delivery. By the third month postpartum, levels were close to, but generally not as high as, those in the month before conception.

We expected that women who were still nursing at the third month postpartum would be lighter drinkers and smokers than women who had never 
Table 4. Relative risks@ ${ }^{@}$ and their $99 \%$ confidence limits for drinking and smoking in third month postpartum: weaned in first month v. nursed more than 3 months and never breastfed v. nursed more than 3 months (relative risks adjusted for preconception use)

\begin{tabular}{lcc}
\hline & $\begin{array}{c}\text { Weaned in first month v. } \\
\text { nursed } \geq 3 \text { months } \\
\text { relative risk } \\
(99 \% \mathrm{CI})\end{array}$ & $\begin{array}{c}\text { Never breastfed v. } \\
\text { nursed } \geq 3 \text { months } \\
\text { relative risk } \\
(99 \% \mathrm{CI})\end{array}$ \\
\hline Any drinking & 1.0 & 1.0 \\
Regular drinking & $(0.85,1.21)$ & $(0.11,8.84)$ \\
Binge drinking & 1.4 & 0.7 \\
Smoking & $(0.88,2.30)$ & $(0.33,1.47)$ \\
& $4.1^{* * *}$ & 1.6 \\
Heavy smoking & $(1.72,9.62)$ & $(0.54,4.83)$ \\
& $1.5^{* * *}$ & $1.4^{* *}$ \\
& $(1.14,1.96)$ & $(1.08,1.89)$ \\
$4.1^{* * *}$
\end{tabular}

(a) The relative risk is interpreted as follows. Consider the comparison of nonbreastfeeders and women who nursed at least 3 months. For any drinking ( $v$. abstaining) at 3 months postpartum, the relative risk is the probability that a non-breastfeeder will be drinking ( $\mathrm{v}$. abstaining) divided by the probability that a woman nursing at 3 months will be drinking ( $\mathrm{v}$. abstaining). A relative risk of 1.0 indicates non-breastfeeders and nursing women are equally likely to be drinking; a relative risk of two would indicate that non-breastfeeders are twice as likely to be drinking as are nursing women. Relative risks for the other variables are interpreted in the same way. If a confidence interval for a given $P$ value includes 1.0 , the relative risk is considered non-significant at that $P$ value.

*** $P<0.001$; ** $P<0.01$.

breastfed or who had weaned early. The data provide only partial support for this expectation when alcohol is considered, since the only significant difference in drinking behaviour was in the occurrence of binges. On the other hand, nursing women were significantly less likely to smoke or smoke heavily at the third month postpartum, regardless of their smoking status before conception. These differences are consistent with the findings of other studies, ${ }^{25-27}$ although the other studies did not take habits before pregnancy into account as we did.

Altered hormone levels have been suggested as the cause of the aversion to alcohol that occurs during pregnancy. ${ }^{28}$ There is no evidence in our data that these or any other biological factors alter the appetite for alcohol during lactation, since the drinking habits of nursing women were not significantly different from those of women who never breastfed. Whether biological factors influence smoking habits during lactation is less clear. Prolactin levels decrease with tobacco use, 
since nicotine blocks its secretion: ${ }^{16-17}$ this may contribute to shortened lactation. ${ }^{29-30}$ It is difficult to tell if there is a strong aversion to tobacco among nursing women since the number who smoked in any period is so small.

What other factors could be responsible for the lower rates of smoking and binge drinking observed among nursing women? A major factor could be the nursing experience itself, which can be intense and time-consuming. Women who have made this commitment of time and emotional energy may have less opportunity and less desire to smoke or drink heavily. Furthermore, women who decide to nurse for several months may also be inclined to decide to limit intake of substance that they feel could be injurious to the baby when taken in milk, or they may be generally less permissive in their attitudes toward drug use than shortterm or non-breastfeeders.

In this study, for example, women who nursed for 3 months were more likely than the other lactation groups not only to cut down on their smoking but to stop entirely. Marijuana use at some time in the 3 -month postpartum period was reported more than three times as frequently by women not nursing in the third month postpartum as by women who were nursing then (14.4\% v. $4.1 \%)$, and cocaine use was more than six times more frequent $(3.3 \% \mathrm{v} .0 .5 \%)$. Stratifying by preconception drug use may have been inadequate to eradicate the influence of attitudes that allow drug use beyond social norms.

Any differences in smoking and drinking habits by lactation history in this study cannot be ascribed to differences in age, education, race, marital status, employment outside the home or parity, since these have been accounted for in the analysis. There is of course the possibility that the results are an artifact: perhaps a third factor influences both the drug use and the lactation decisions.

The chief limitation of this study is that the sample is highly selected. Women who received prenatal care after the sixth month of pregnancy were not included. Furthermore, $26 \%$ of those chosen to be in the study did not participate, and some of those who did failed to complete all parts of it. The primary reason for nonparticipation was that we were not permitted to contact subjects directly. The time between when an eligible patient was first identified by the Cooperative and when that patient finally contacted us could be several months, possibly too late for study. This time-lag was the chief reason why the sample was restricted to women seen for prenatal care by the sixth month of gestation. Other patients who might have participated had we spoken to them personally chose not to contact us at all. The relatively low participation rate, while unavoidable, may have introduced selection bias into the study if those who arrived late for prenatal care or did not volunteer for study were different from the sample in their drinking, smoking or breastfeeding habits.

The other limitations of this study must also be borne in mind. The sample was drawn from a homogeneous group of low-risk women, and the results should not be generalised to other higher risk populations. Women who weaned between 1 
and 3 months after delivery were excluded by design. There were few heavy drinkers and heavy smokers in the sample. The differences in drinking and smoking patterns by lactation history were not always large and were based on small numbers. The difference could have been a reflection of inadequately controlled patterns of preconception use, in spite of efforts to take this into account. Future studies can be designed to address these limitations and clarify the role of the many factors that could influence decisions during lactation. Behaviour is a complex phenomenon and simple explanations are seldom sufficient.

\section{Acknowledgements}

This work was funded by Research Grant \#HD14689 and supported by the Alcoholism and Drug Abuse Institute of the University of Washington. We gratefully acknowledge the co-operation of Group Health Cooperative of Puget Sound.

\section{References}

1 Streissguth, A.P., Landesman-Dwyer, S., Martin, J.C. et al. Teratogenic effects of alcohol in humans and laboratory animals. Science 1980; 209:353-361.

2 Landesman-Dwyer, S., Emanuel, I. Smoking during pregnancy. Teratology 1979; 19:119-125.

3 Hook, E.B. Changes in tobacco smoking and ingestion of alcohol and caffeinated beverages during early pregnancy. In: Birth Defects: Risks and Consequences. Editor: S. Kelly. New York: Academic Press, 1976.

4 Little, R.E., Schultz, F.A., Mandell, W.A. Drinking during pregnancy. Journal of Studies on Alcohol 1976; 37:375-379.

5 Luck, W., Nau, H. Nicotine and cotinine concentrations in serum and urine of infants exposed via passive smoking or milk from smoking mothers. Journal of Pediatrics 1985; 107:816-820.

6 Ferguson, B.B., Wilson, D.J., Schaffner, W. Determination of nicotine concentrations in human milk. American Journal of Diseases of Children 1976; 130:837-839.

7 Kesaniemi, Y.A. Ethanol and acetaldehyde in the milk and peripheral blood of lactating women after ethanol adminstration. Journal of Obstetrics and Gynecology of the British Commonwealth 1974; 81:84-86.

8 Lawton, M.E. Alcohol in breast milk. Australia and New Zealand Journal of Obstetrics and Gynaecology 1985; 25:71-73.

9 Bisdom, C.J.W. Alcohol and nicotine poisoning in infants (sucklings). Maandscrift voor Kindergeneeskunde 1937; 6:332-341.

10 Binkiewicz, A., Robinson, M.J., Senior, B. Pseudo-Cushing syndrome caused by alcohol in breast milk. Journal of Pediatrics 1978; 93:965-967.

11 Anderson, P. Drugs and nursing. Drug Intelligence and Clinical Pharmacology 1971; 11:208-223.

12 Detering, N., Reed, W.D., Ozand, P.T. et al. Effects of maternal ethanol consumption in the rat on the development of their offspring. Journal of Nutrition 1979; 109:999-1009. 13 Diaz, J., Samson, H.H. Impaired brain growth in neonatal rats exposed to ethanol. Science 1980; 208:751-753. 
14 Hamosh, M., Simon, M.R., Hamosh, P. Effect of nicotine on the development of fetal and suckling rats. Biology of the Neonate 1979; 35:290-297.

15 Becker, R.F., Martin, J.C. Vital effects of chronic nicotine absorption and chronic hypoxic stress during pregnancy and the nursing period. American Journal of Obstetrics and Gynecology 1971; 110:522-533.

16 Terkel, J., Blake, C.A., Hoover, V. et al. Pup survival and prolactin levels in nicotinetreated lactating rats. Proceedings of the Society for Experimental Biology and Medicine 1973; 142:1131-1135.

17 Blake, C.A., Sawyer, C.H. Nicotine blocks the suckling-induced rise in circulating prolactin in lactating rats. Science 1972; 177:619-621.

18 Carver, J.W., Nash, J.B., Emerson, G.A. et al. Effects of pregnancy and lactation on voluntary alcohol intake of hamsters. Joumal of Pharmacology and Experimental Therapeutics 1953; 12:309.

19 Emerson, G.A., Brown, R.G., Nash, J.B. et al. Species variation in preference for alcohol and in effects of diet or drugs on this preference. Journal of Pharmacology and Experimental Therapeutics 1952; 11:384.

20 Komura, S., Niimi, Y., Yoshitake, Y. Alcohol preference during reproductive cycle in female C57BL mice. Japan Journal of Studies on Alcohol 1970; 5:91-96.

21 Randall, C.L., Lochry, E.A., Hughes, S.S. et al. Decreased ethanol consumption as a function of pregnancy and lactation in C57BL mice. Pharmacology, Biochemistry and Behavior 1980; 13:149-153.

22 Little, R.E., Uhl, C.N., Labbe, R.F. et al. Agreement between laboratory tests and selfreports of alcohol, tobacco, caffeine, marijuana and other drug use in post-partum women. Social Science in Medicine 1986; 22:91-98.

23 Jessor, R., Graves, T.D., Hanson, R.C. et al. Society, Personality, and Deviant Behavior: A Study of a Tri-Ethnic Community. New York: Holt, Rinehart' Winston, 1968.

24 Rothman, K. Modern Epidemiology. Boston: Little, Brown, 1986.

25 Lyon, A.J. Effects of smoking on breast feeding. Archives of Diseases of Children 1983; 58:378-380.

26 Counsilman, J.J., Mackay, E.V. Cigarette smoking by pregnant women with particular reference to their past and subsequent breast feeding behavior. Australia and New Zealand Journal of Obstetrics and Gynaecology 1985; 25:101-107.

27 Stahlberg, M.R. Breast-feeding and social factors. Acta Paediatrica Scandinavica 1985; 74:36-39.

28 Weathersbee, P.S., Lodge, J.R. A review of ethanol's effects on the reproductive process. Journal of Reproductive Medicine 1978; 21:63-78.

29 Andersen, A.N., Lund-Andersen, C., Larsen, J.F. et al. Suppressed prolactin but normal neurophysin levels in cigarette smoking breast-feeding women. Clinical Endocrino$\log y$ 1982; 17:363-368.

30 Baron, J.A., Bulbrook, R.D., Wang, D.Y. et al. Cigarette smoking and prolactin in women. British Medical Journal 1986; 293:482-483. 